\title{
The result of an experimental study of the processing of silkworm cocoons
}

\author{
Shovqiddin Zulpanov ${ }^{1}$, Shakhnoza Sultanova ${ }^{1}$, Dildora Sobirova ${ }^{1}$, Marko Petković ${ }^{2}$, Jasur Safarov ${ }^{1 *}$ \\ ${ }^{1}$ Tashkent state technical university, University str. 2, Tashkent, Uzbekistan \\ ${ }^{2}$ University of Kragujevac, Faculty of Agronomy, Department of Food Technology, Cara Dušana 34, Čačak, Serbia
}

\begin{abstract}
To ensure uniform temperature in the infrared vibratory drying unit and to preserve the quality of the final product during the initial processing of silkworm cocoons, the temperature field was studied using a thermal imager. Using a thermal imager, you can measure the temperature in contactless and remote processes. At the same time, you can obtain temperature information from several points. The thermal imager measures infrared radiation in the long-wavelength range within the field of view and automatically detects cold and hot spots. Based on this, the temperature of the measured object is calculated. The thermal image appears on the thermal imager screen and the obtained image results are processed on a computer.
\end{abstract}

Key words: silkworm cocoons, drying, thermal process.

\section{Introduction}

The program for the development of silkworm cultivation and processing of silkworm cocoons of the Republic of Uzbekistan in recent years provides conditions for the restoration and development of the silkworm industry, providing silkworms with high-quality local croutons, increasing the volume of production of silkworm cocoons, increasing the silkworm's feed base and providing silkprocessing enterprises with high-quality raw materials.

Cocoons produced by silkworm caterpillars are one type of natural structure and polymer composite materials that have excellent mechanical properties. Having eaten the leaves of the mulberry tree almost constantly for 4-6 weeks (in order to preserve a sufficient amount of nutrients and be able to strip the skin up to five times), silkworm larvae begin to create protective cocoons for their pupae. The cocoon protects the moth pupa from microbial degradation and drying during metamorphosis, and also protects it from potential predators. A silkworm caterpillar rotates a light and compact cocoon around itself, continuously carrying out head movements in the form of an "8" or "S", and cyclically bending, stretching its body. It takes about 3 days to build a cocoon. After the silkworm finishes wrapping itself in a cocoon, it discards its skin for the last time and becomes a chrysalis [1].

Cocoon production is the most developed of the silkworm Bombyx mori - a typical insect. Mulberries are propagated in large quantities to produce silk. There are more than 1000 strains including various geographical and mutant strains. Among them are many colored mutants, including white, yellow, golden yellow, orange, pinkish and green [1].
Silkworm cocoons are biological composite structures that protect silkworms from environmental influences and physical attacks of natural predators. Silkworm pupae must be killed to obtain raw materials in the textile industry. For the death of pupae, drying of cocoons is used without allowing them to turn into a moth (butterfly), otherwise it will leave the cocoon, breaking through the shell, making it useless. The Seminar on Experimental Art (Sericultural Experiment Station - S.E.S.) [2] also states that fresh cocoons contain living pupae, which in the natural cycle will break through the cocoon and make it useless for silk production. To control the cycle, the pupae must be starved and the cocoons handled so that they can be stored and used in the winding process as needed. The percentage of moisture content varies depending on the variety of silkworms, growing season, on the floor of the caterpillars, etc. [3].

Cocoons can be killed using steam or hot air. Many studies show that the purpose of drying the cocoon is to prevent the appearance of larvae and moths and to remove moisture contained in the shell of the cocoon and pupae, and thereby make cocoons capable of preserving for a long time at normal temperature and humidity [3]. Several industrial drying methods have been aimed at killing pupae by placing cocoons on perforated mats or in wire boxes where they are exposed to water vapor for three hours. After that, the cocoons are dried. The most commonly used method used to kill and dry pupae involves blowing heated air with a temperature of 50 to $102 \pm 2{ }^{\circ} \mathrm{C}$ vertically, through the grill, through cocoons placed in mesh bags.

Most of the water (75-79\%) is contained in the puppet body, while the fresh shell of the cocoon contains (11-12\%). For this reason, fans must be designed to provide an air speed of $1.0 \mathrm{~m} / \mathrm{s}$. Air heated to $102 \pm 2{ }^{\circ} \mathrm{C}$ is sufficient to allow

\footnotetext{
${ }^{*}$ Corresponding author

E-mail: jasursafarov@yahoo.com
} 
quick drying. Air temperatures above $115 \pm 5{ }^{\circ} \mathrm{C}$ may affect the sericin content. So, in the winding process, it is observed that the efficiency of the end ends and the decrease in the ability of the drums leads to a decrease in the proportion of raw silk in the cocoon. P.Wu et al. [4] showed that the main goal of drying silkworm cocoons is to kill pupae and reduce the potentially hazardous moisture content, which allows cocoons to be stored for up to a year in appropriate conditions. Therefore, silkworm cocoons must be dried immediately after harvest due to the possibility of the appearance of moths from the pupae that they contain, and can spoil an important feature of the cocoons from the inside, which leads to the rolling of raw materials. Proper drying allows cocoons to withstand long-term storage (6-12 months) without mold. The whole dried cocoon has a moisture content of about $(8-12 \%)$ and $(6-8 \%)$ in the shell of the cocoon, while the body of the dried pupae contains about (7-13\%). EK Nguku et al. The authors of [5] showed that drying in the sun is still the most common method for storing cocoons. Due to the lack of sufficient storage methods, cocoons are dried in thin layers on paved bases or mats, where they are exposed to sunlight and wind for 3-5 days.

Silkworm (Latin Bombyx mori), or silkworm - caterpillar and butterfly. Mulberry silkworm is the only fully domesticated insect not found in nature in the wild. Females even "forgot how" to fly. An adult insect is a thick butterfly with whitish wings up to $6 \mathrm{~cm}$ wide. The caterpillars of this silkworm eat only the leaves of mulberry, or mulberry tree. Silkworm caterpillars curl cocoons, the shells of which consist of a continuous silk thread 300-900 m long and up to $1500 \mathrm{~m}$ in the largest cocoons [6-8].

Natural silk has been known to mankind for more than five thousand years. All this time he was considered the most elite and luxurious material. The reasons for the popularity of silk fabrics lie in the special composition of raw materials and the unique properties of silk thread. Indeed, by its nature, natural silk consists of $97 \%$ of fibrous proteins and 18 amino acids that positively affect human metabolism. This is a very gentle, light and surprisingly warm material, contrary to the opinion of the coldness of its touch [9-13].

\section{Results and Discussions}

To ensure a uniform temperature in an infrared vibratory drying unit and to preserve the quality of the final product during the initial processing of silkworm cocoons, the temperature field was studied using a thermal imager shown in Fig. 1 [14-17].

Using a thermal imager, you can measure temperature in non-contact and remote processes. At the same time, you can obtain temperature information from several points. The thermal imager measures infrared radiation in the longwavelength range within the field of view and automatically detects cold and hot spots. Based on this, the temperature of the measured object is calculated. The thermal image appears on the thermal imager screen and the obtained image results are processed on a computer. The temperature measurement range is from $-30{ }^{\circ} \mathrm{C}$ to $+650{ }^{\circ} \mathrm{C}$, image quality is $320 \times 240$ pixels, the spectral range is $7.5-14 \mu \mathrm{m}$, the error is $\pm 2{ }^{\circ} \mathrm{C}$ $(2 \%)$.

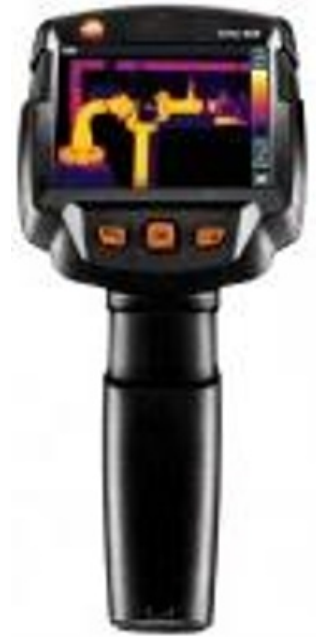

Fig. 1. The thermal imager Testo 868

Laboratory experiments were carried out and temperature fields were studied in an infrared vibratory drying unit during the initial processing of silkworm cocoons (Fig. 3-7).

On the basis of the obtained theoretical results, an experimental infrared vibration unit was developed at the Tashkent State Technical University, which allows carrying out the process of carrot and drying of the optimal parameters of the processed silkworm cocoons (Fig. 2).

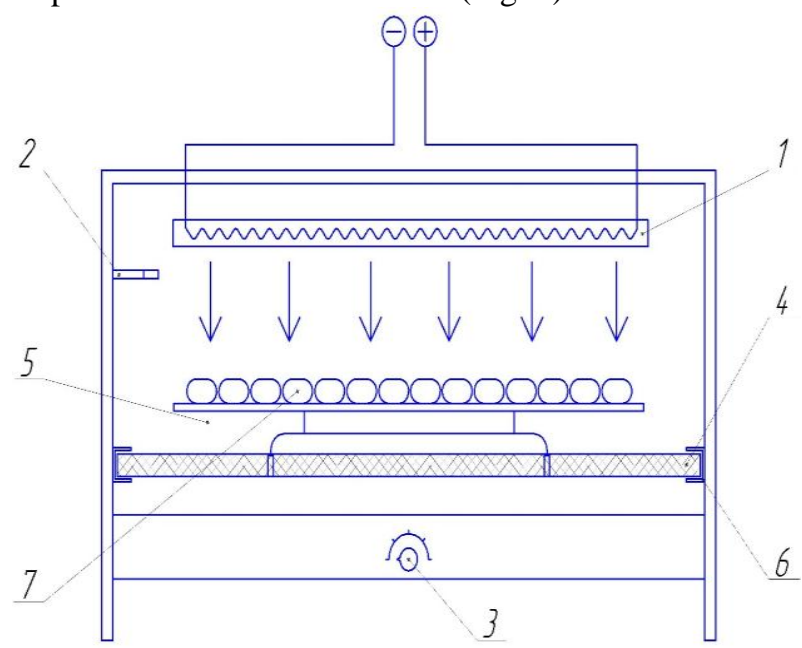

1-IR heater; 2-thermocouple; 3-thermostat; 4-pallet;

5-scales with digital display; 6-stand; 7-raw material.

Fig. 2. Laboratory experimental IR-drying equipment

This installation allows to carry out research: calculation of the technological process of preliminary processing of a living silkworm using infrared rays; analysis of acoustic and vibration elastic waves and low temperature; carrying out works aimed at the energy efficiency of the installation; process control of an energy-saving and low-temperature plant for high quality products. This method is used to calculate the technological process of preliminary processing of a living silkworm with infrared rays, thereby achieving energy conservation and improving the quality of the product.

As a result of the research, the optimal temperature and time for the primary processing of silkworm cocoons were found. Due to short-term processing, the final product is improved. 

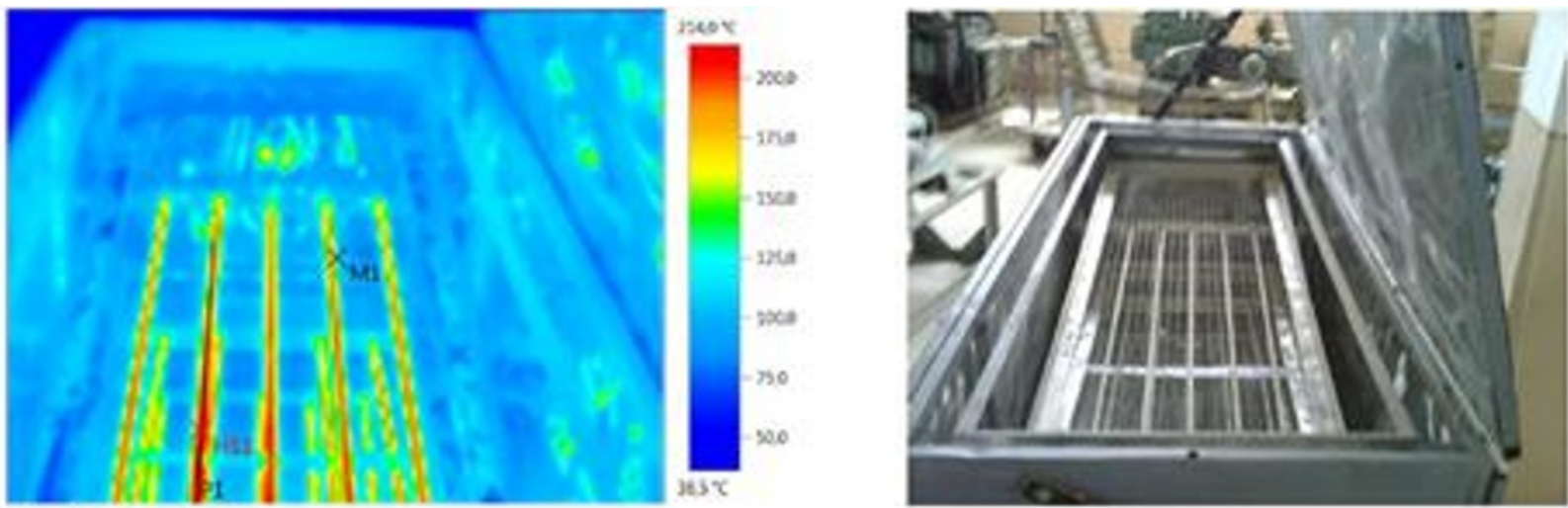

Emissivity: 0.93

Reflection temperature $\left({ }^{\circ} \mathrm{C}\right): 22.0$

Selecting images

\begin{tabular}{|l|c|c|c|l|}
\hline \multicolumn{1}{|c|}{ Measured objects } & $\begin{array}{c}\text { Temperature } \\
\left({ }^{\circ} \mathrm{C}\right)\end{array}$ & Radiation & $\begin{array}{c}\text { Reflection } \\
\text { temperature }\left({ }^{\circ} \mathrm{C}\right)\end{array}$ & Notes (edit) \\
\hline Measurement point 1 & 107,7 & 0,93 & 22,0 & CenterSpot \\
\hline Coldest point 1 & 36,5 & 0,93 & 22,0 & - \\
\hline Warmest point 1 & 214,0 & 0,93 & 22,0 & - \\
\hline
\end{tabular}

Fig. 3. Thermal image of IR emitters
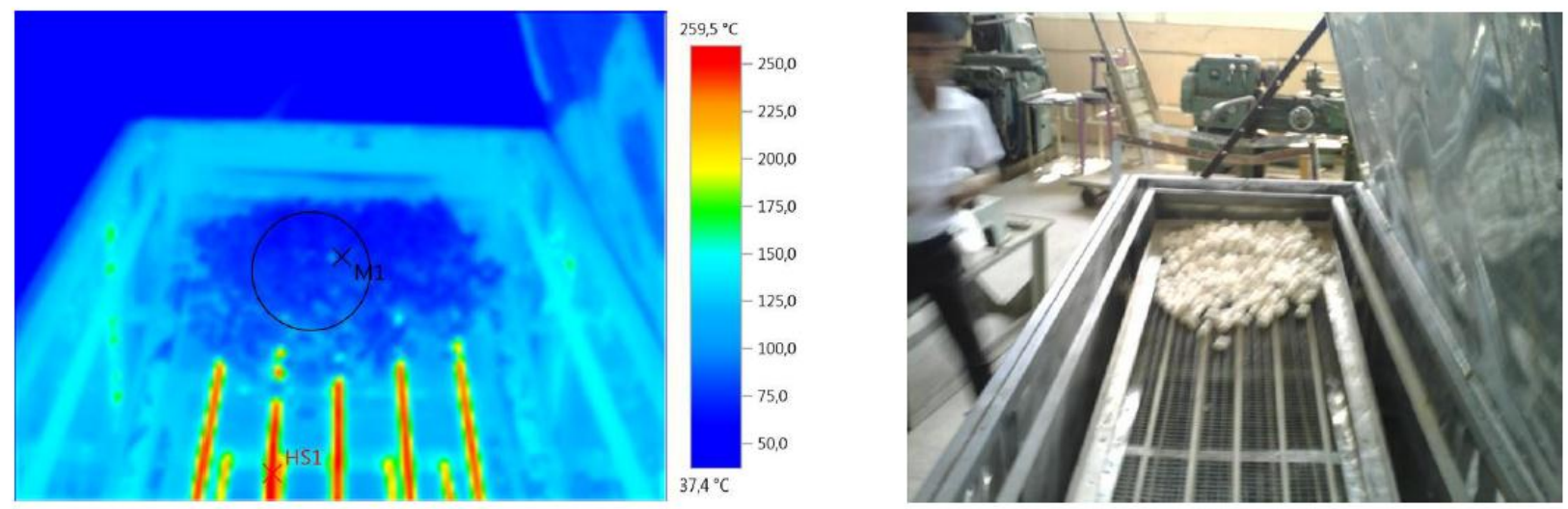

Fig. 4. The primary processing cocoons
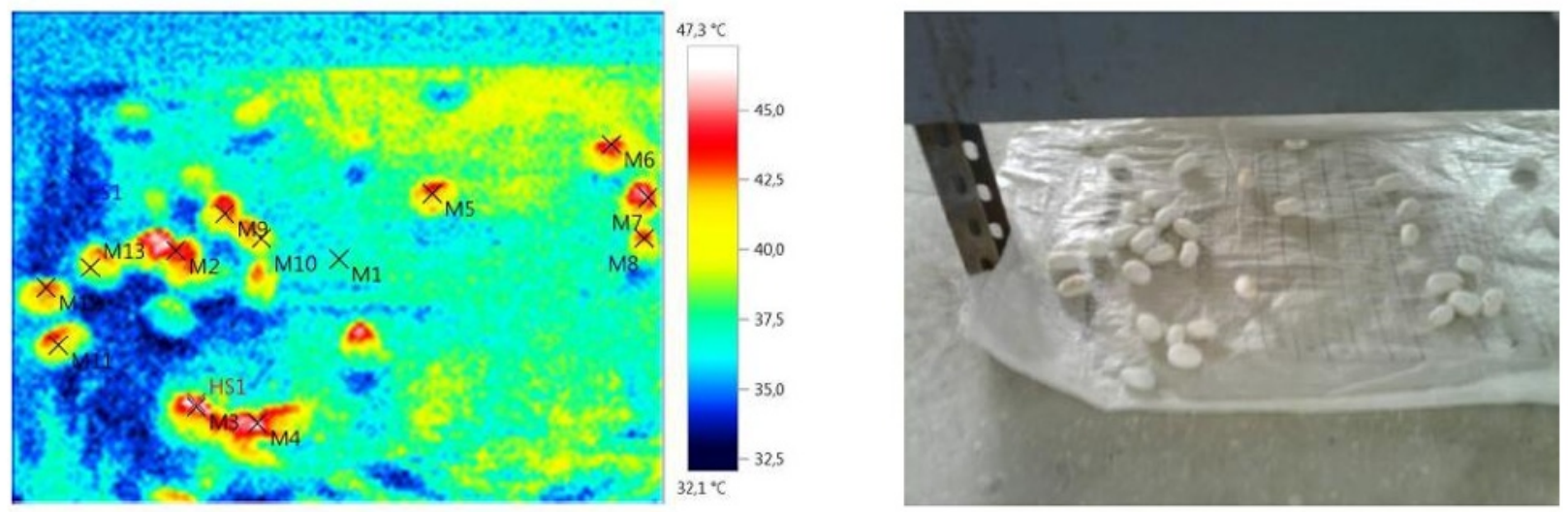

Fig. 5. Temperature measurement of dried cocoons 


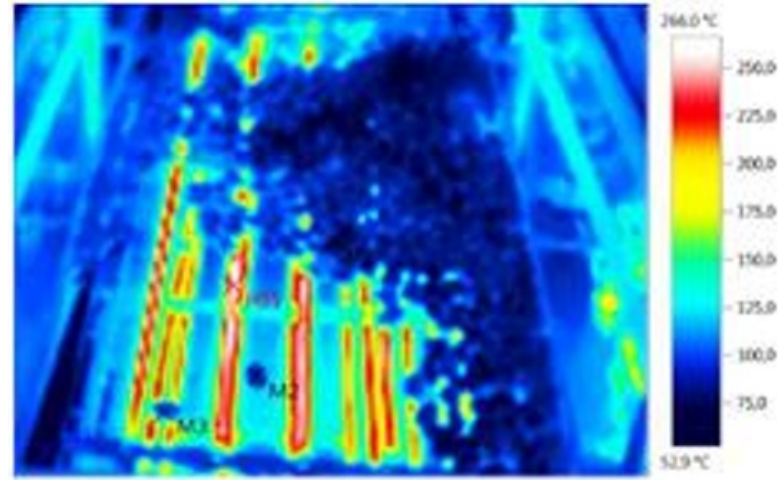

Emissivity: 0.93

Reflection temperature $\left({ }^{\circ} \mathrm{C}\right): 22.0$

Selecting images

\begin{tabular}{|l|c|c|c|l|}
\hline \multicolumn{1}{|c|}{ Measured objects } & $\begin{array}{c}\text { Temperature } \\
\left({ }^{\circ} \mathrm{C}\right)\end{array}$ & Radiation & $\begin{array}{c}\text { Reflection } \\
\text { temperature }\left({ }^{\circ} \mathrm{C}\right)\end{array}$ & Notes (edit) \\
\hline Measurement point 1 & 66,3 & 0,93 & 22,0 & CenterSpot \\
\hline Measurement point 2 & 73,3 & 0,93 & 22,0 & - \\
\hline Measurement point 3 & 82,7 & 0,93 & 22,0 & - \\
\hline Coldest point 1 & 52,9 & 0,93 & 22,0 & - \\
\hline Warmest point 1 & 266,0 & 0,93 & 22,0 & - \\
\hline
\end{tabular}

Fig. 6. Measuring the temperature of the drying process of cocoons
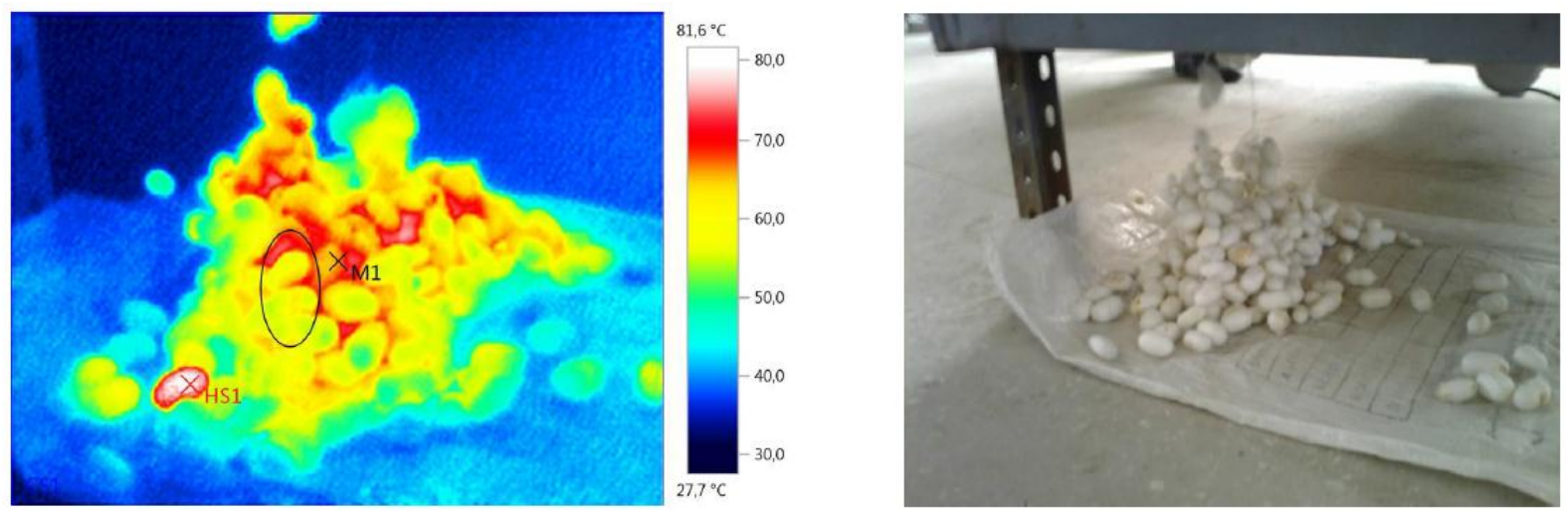

Fig. 7. Drying cocoons processing results

Administration, Republic of Korea. Pp. 294-305 (1992).

3. P.V. Narasaiah Sericulture in India. Ashish Publishing House. Punjabi Bagh, New Delhi, (1992).

\section{Conclusion}

Based on the results of the study, the imager eliminated the shortcomings of the infrared vibratory drying unit associated with the emitters and the flow of heat during the initial processing of cocoons, determined the optimal temperatures and ensured uniform processing of silkworm cocoons.

\section{References}

1. Y.T. Hendaw, Stifling Cocoons Silkworms Using Butane Gas Mechanical Dryer. J.Soil Sci. and Agric. Eng., Mansoura Univ., Vol. 8(4):149 - 156 (2017).

2. S.E.S. Guide to Sericultural Technology in the Tropics. Sericultural Experiment Station. Role Development
4. P. Wu, C. Da-Chuang, C. Zou-Pu, L. Ping-Zhang, T. He, Silkworm rearing Publisher. FAO Agric Services. Rome. 73/2. p. 69-70 (1992).

5. E.K. Nguku, S.K. Raina, K.G. Mburugu, O.M. Mugenda, Evaluation of Different Cocoon Stifling Methods on Raw Silk Quality. Published in the African Journal of Applied Human Sciences. 1(1). pp 4-8 (2009).

6. N. Mukhtarova, B. Aliev, S. Turabdzhanov, L Rakhimova. Studies of factors affecting stability and efficiency of anion exchanger. E3S Web of Conferences. 177, 03020 (2020).

7. G.A. Ikhtiyarova, B.N. Umarov., S.M. Turabdjanov, A.N. Axmadjonov, C.Q. Haydarova Physicochemical properties of chitin and chitosan from died honey bees apis mellifera of Uzbekistan. Journal of Critical Reviews. 7(4) p.120-124 (2020).

8. S. Turabdzhanov, Z. Nazirov, D. Turaeva, L. Rakhimova. 
Perspective wastewater treatment from $\mathrm{Cu} 2+$ ions in the mining industry. E3S Web of Conferences. 105, 02025 (2019).

9. H.Z. Igamberdiyev, A.N. Yusupbekov, O.O. Zaripov, J.U. Sevinov. Algorithms of adaptive identification of uncertain operated objects in dynamical models. Procedia Computer Science. 120. p.854-861 (2017).

10. I.U. Rakhmonov, F. Hoshimov. Development of an Algorithm for Evaluating the Dominant Factors that have the Greatest Impact on the Energy Intensity of Products. E3S Web of Conferences, 209, 07018 (2020).

11. F.A. Hoshimov, I.U. Rakhmonov, N.N. Niyozov. Technology to Reduce Energy Costs in the Electric Steel Melting Shop. E3S Web of Conferences, 209, 07017 (2020).

12. I.U. Rakhmonov, N.N. Kurbonov. Analysis of automated software for monitoring energy consumption and efficiency of industrial enterprises. E3S Web of Conferences, 216 , 01178 (2020).

13. I.U. Rakhmonov, K.M. Reymov. Statistical models of renewable energy intermittency. E3S Web of Conferences, 216, 01167 (2020)

14. J.E. Safarov, Sh.A. Sultanova, G.T. Dadayev, Sh.U. Zulpanov. Influence of the structure of coolant flows on the temperature profile by phases in a water heating dryer. IOP Conference Series: Materials Science and Engineering, 1029(1), 012019 (2021).

15. J. Safarov, A. Khujakulov, Sh. Sultanova, U. Khujakulov, Sunil Verma. Research on energy efficient kinetics of drying raw material. E3S Web of Conferences: Rudenko International Conference "Methodological problems in reliability study of large energy systems" (RSES 2020) 216, p.1-5 (2020).

16. Sh. Sultanova, J. Safarov, A. Usenov, T. Raxmanova. Definitions of useful energy and temperature at the outlet of solar collectors. E3S Web of Conferences, 216, 01094 (2020).

17. J.E. Safarov, Sh.A. Sultanova, G.T. Dadayev, D.I. Samandarov Method for the primary processing of silkworm cocoons (Bombyx Mori). International Journal of Innovative Technology and Exploring Engineering. 9(1), p.4562-4565 (2019). 